\title{
The Effect of Health Education and Antibiotic use on the Prevalence of Trachoma in School Children in Borno State of Northern Nigeria.
}

\author{
Adah O. S, Zoakah I.A, Ogbonna C., Obadiah M, Ogiri S, Shown L.D, Envuladu \\ E.A, Banwat M.E and Bupwatda $P$
}

\author{
Correspondence: Dr. S.Adah, Department of Community Medicine, Jos University teaching Hospital \\ e-mail:adahsteve@yahoo.com
}

\begin{abstract}
Trachoma is one of the leading causes of blindness worldwide and the leading cause of preventable blindness. ${ }^{l}$ It is endemic in Africa, the Eastern Mediterranean Region, Australia and parts of Southeast Asia. ${ }^{2}$ Trachoma is caused by the recurrent, chronic infection of the eye with Chlamydia trachomatis and progresses from inflammation to conjunctiva scarring, lid deformities, corneal abrasion and visual impairment.
\end{abstract}

Methods:This was a school- based cross- sectional descriptive study among primary school pupils in Bama Local Government Area of Borno state. Simple random sampling technique by balloting was used to select the subjects for the study. A total of three hundred subjects were studied.

Results:The prevalence of active trachoma in the schools were 32(20.9\%) at Bama central Primary school, 36(23.4\%) at Soye primary school. The prevalence of active trachoma in the male population was 19(52.8\%). In both schools, the prevalence of active trachoma was highest amongst the 5-9 years age group, followed by the 10-14 years age group.

Conclusion:Health education and antibiotic use reduced the prevalence of trachoma in school children in Borno State.

Keywords: Health education, Prevalence, Trachoma

\section{Introduction}

Trachoma is one of the leading causes of blindness worldwide and the leading cause of preventable blindness. ${ }^{1}$ It is endemic in Africa, the Eastern Mediterranean Region, Australia and parts of Southeast Asia. ${ }^{2}$ Trachoma is caused by the recurrent, chronic infection of the eye with Chlamydia trachomatis and progresses from inflammation to conjunctiva scarring, lid deformities, corneal abrasion and visual impairment. The blinding sequelae, which occur in middle age, is felt to be the result of numerous or lengthy episodes of severe inflammatory trachoma in childhood. It is the most common infectious cause of blindness, and is responsible for an estimated $15 \%$ of global blindness. ${ }^{3,4}$ Progressive scarring from these infections causes a cascade of effects: entropion, trichiasis, corneal infections, corneal scarring, and ultimately blindness. ${ }^{5}$

The World Health Organization (WHO), in collaboration with various Non Governmental Organizations and National Health Services, recently began implementing a programme to eliminate blinding trachoma, captioned Global Elimination of Trachoma by 2020 (GET 2020). ${ }^{6,7}$
This programme has adopted a strategy consisting of the following control measures: Surgery for entropion/trichiasis; Antibiotics for infectious trachoma; Facial cleanliness to reduce transmission; and Environmental improvements such as control of disease spreading flies and access to clean water (SAFE) ${ }^{8}$ At present trachoma is still the world's leading infectious cause of blindness and the leading cause of ocular morbidity. ${ }^{9}$ It is estimated by WHO that at present there are 146 to 150 million people worldwide with trachoma: 10 to 10.6million suffer from trichiasis and need surgery to prevent corneal blindness from developing. ${ }^{10,11,12}$ Trachoma causes one-quarter of the world's blindness, and although it has disappeared from many developed areas, it remains a major problem, especially in underprivileged rural areas in developing countries. ${ }^{13}$

\section{Objective}

To determine the effect of health education and antibiotic use in the prevention of active trachoma eye infection in school children. 


\section{Materials and Methods}

\section{Background Information of Study Area}

This study was carried out among primary school pupils in Bama Local Government Area of Borno state. Borno state lies in the North Eastern part of Nigeria and it has 27 Local Government Areas (LGAs). There are two vegetational zones (Sahara desert in the Northern half and Sudan savannah in the southern half) and two seasons, dry season from October to April and rainy season from May to September. The total land area is $69,436 \mathrm{~m}^{2}(20.7 \%$ of National land mass). The population of the state is $2,596,589$ million people. ${ }^{14}$

Bama LGA has a population of 265,578 people. ${ }^{15}$ Sharing border with Cameroon and at the fringe of the Sahara desert, an arid and very sandy region with plenty of flies. The LGA is an agrarian society with poor environmental sanitation. Their main water supply is from deep wells and boreholes.

The rural people live together with their animals. Few households have latrines and open defecation is a common practice. Islam is the predominant religion in the area. The ethnic groups are the Kanuris, the Mandaras and the Shua Arabs. The Kanuris and the Mandaras are basically farmers and the Shua Arabs are nomads.

There are eighty primary schools, nine secondary schools, and an Advance Teacher's Science and Technical College, a General Hospital and 30 primary health care facilities in the LGA.

\section{Study Design}

This was a school based cross sectional study design. The two schools were randomly selected by simple balloting.

\section{Study Population}

The study population consisted of pupils selected randomly by using a table of random numbers. The class registers constituted the sampling frames from all the arms of each class in Bama Central primary school and Soye Primary school.

\section{Sample Size}

The minimum sample size calculated was 300 pupils.

\section{Sampling Method}

A multistage sampling method was applied in this study. The districts were the first stage units and the schools the second stage units. At the third stage, to ensure equal representation of all classes and sex, each primary school selected was stratified based on class and sex. At the forth stage the pupils in each school were selected randomly using table of random numbers by proportionate allocation based on class and sex using the class registers as sampling frames.

\section{Instruments of Data Collection}

The instruments of collection were; school pupils' questionnaires, a check list on the schools environment, a loupe (*22.5) (opti Visor), 60 leave note books, pencils, biros, a torch light, and plain sheets of paper. The questionnaires were pre tested in Gwoza central primary school in Gwoza LGA.

\section{Data Collection Techniques}

Well- trained ophthalmic Nurses (by Helen Keller International trachoma control project) were used to administer the questionnaires on factors contributing to trachoma transmission in the pupils' home and within the school premises. The Nurses also screened the pupils for active trachoma by examining their eyes, using the WHO Simplified Trachoma Grading Scale, ${ }^{16}$ based on clinical examination with a loupe $(* 22.5)$ (opti Visor) and a hand torch as a light source.

Active trachoma consists of;

Trachomatous inflammation follicular (TF)

Trachomatous inflammation intense (TI). ${ }^{16}$

The screening was carried out by flipping the upper eyelid upwards and exposing the tarsal plates. With active trachoma infection, the internal part of the upper eyelids is red, with or without visible pale or white spots (Follicle); occasionally, copious secretions from the eyelids were observed. The presences of red eye, acute conjunctival eye infections were also noted.

\section{Data Processing and Analysis}

The data of this study was processed and analyzed manually using master sheet, construction of dummy tables and by the use of EPI info version 2000, an epidemiological software computer programme. $^{17}$

\section{Ethical Considerations}

Permission was obtained from the Ethical Clearance Committee board of the Jos University Teaching Hospital; the pupils were given the consent forms to take home to their parents for signing and permission. The nature, aims and objectives of the study were explained to the headmasters, the teachers, the representatives of the PTA, and the pupils. Their consent was sought in writing. The pupils were given the option to opt out 
of the study if they so wish without affecting any benefit accruing to them.

\section{Limitation of Study}

All pupils in each school were not screened for trachoma at the time of study.

Results

\section{Prevalence of Active Trachoma (Tf/Ti) In Study Schools}

In all, a total of 307 pupils were screened in the two schools, 153 pupils in Bama Central Primary school and 154 pupils in Soye Primary school. The overall prevalence in the two schools was 68 pupils $(22.2 \%)$ of active trachoma and 4 pupils $(1.3 \%)$ had trichiasis (TT). The prevalence of active trachoma in the schools were $32(20.9 \%)$ at Bama central Primary school, 36(23.4\%) at Soye primary school.

\begin{tabular}{l|c|cc}
\multicolumn{5}{l}{ TABLE 1: PREVALENCE OF ACTIVE TRACHOMA (TF/TI) In Both Schools } \\
\hline & Bama central primary school & Soye Primary school & \\
\hline $\begin{array}{l}\text { Active } \\
\text { Trachoma } \\
\text { TF/TI }\end{array}$ & Freq \% & Freq \% & Total \\
Present & $32(20.9)$ & $36(23.4)$ & $68(22 . .1)$ \\
& & & \\
Absent & $121(79.1)$ & $118(76.6)$ & $239(77.9)$ \\
& & & $307(100)$ \\
\hline Total & $153(100.0)$ & $154(100.0)$ & \\
\hline
\end{tabular}

PREVALENCE OF ACTIVE TRACHOMA (TF/TI) IN BOTH SCHOOLS BY SEX

The prevalence of active trachoma in the male population was $22(68.8 \%)$ in Bama Centra Primary school. The prevalence of active trachoma in the male population was $19(52.8 \%)$.

TABLE 2: PREVALENCE OF ACTIVE TRACHOMA (TF/TI) IN Both Schools BY SEX.

\begin{tabular}{llll|lll}
\hline \multicolumn{5}{l|}{ Bama Central Primary school } & \multicolumn{3}{l}{ Soye Primary school } \\
\hline SEX & $\begin{array}{l}\text { Number } \\
\text { Studied }\end{array}$ & TF/TI & $\%$ & $\begin{array}{l}\text { Number } \\
\text { Studied }\end{array}$ & TF/TI & $\%$ \\
\hline & & & & & & \\
Male & 98 & 22 & 68.8 & 76 & 19 & 52.8 \\
& & & & & & \\
Female & 55 & 10 & 31.2 & 78 & 17 & 47.2 \\
\hline TOTAL & 153 & 32 & 100.0 & 154 & 36 & 100.0 \\
\hline
\end{tabular}

PREVALENCE OF ACTIVE TRACHOMA (TF/TI) IN BOTH SCHOOLS BY AGE In both schools, the prevalence of active trachoma was highest amongst the 5-9 years age group, followed by the 10-14 years age group.

TABLE 3: PREVALENCE OF ACTIVE TRACHOMA (TF/TI) IN STUDY AND CONTROL SCHOOLS BY AGE AT BASELINE.

\begin{tabular}{|c|c|c|c|c|c|c|}
\hline \multirow[b]{2}{*}{ Age Group } & \multicolumn{3}{|c|}{ Bama Central Primary School } & \multicolumn{3}{|c|}{ Soye Primary school } \\
\hline & Number Studied & $\mathrm{TF} / \mathrm{TI}$ & $\%$ & Number Studied & $\mathrm{TF} / \mathrm{TI}$ & $\%$ \\
\hline $5-9$ & 69 & 21 & 65.6 & 92 & 30 & 83.3 \\
\hline $10-14$ & 83 & 11 & 34.4 & 62 & 6 & 16.7 \\
\hline$>15$ & 1 & 0 & 0 & 0 & 0 & 0 \\
\hline TOTAL & 153 & 32 & 100.0 & 154 & 36 & 100.0 \\
\hline
\end{tabular}

\section{Discussion}

A total of three hundred and seven pupils were recruited for this study. One hundred and fifty three from Bama central primary school and one hundred and fifty four from Soye primary school with mean ages of $9.6 \pm 2.0$ and $8.5 \pm 2.3$ for Bama and Soye, respectively. The overall prevalence of active trachoma in both schools was 68(22.1\%). The prevalence of active trachoma (TI/TF) was $20.9 \%$ in Bama central primary school and $23.4 \%$ at Soye primary school.

The findings of this study with respect to prevalence of active trachoma in both schools were in agreement with findings of earlier study in Bama L.G.A. where the prevalence of active trachoma was $31.7 \%$ with a range of $10 \%$ to $41.8 \%$ in the general population in different districts, ${ }^{18}$ and in Jos where the prevalence of trachoma was $19.4 \%$ in a group of schools attended by children of the poor living in the sub-urban area of the town. ${ }^{19}$

The prevalence in the study population was lower than the general population probably due the facial hygiene seen in some of the school children.

The findings were also in agreement with the overall prevalence in Nigeria where active trachoma is $20.2 \%{ }^{8}$ The prevalence findings in this study were higher than the findings in previous studies in Plateau State, where the prevalence of active trachoma in children under ten years of age was $7 \%$, in Nassarawa State where the prevalence was $8 \%{ }^{20}$ and $11.8 \%$ in another study in Northern Nigeria. ${ }^{21}$ The similarities and differences seen in the prevalence of active trachoma in these studies could be attributed to environmental and socioeconomic conditions existing in these study areas.

Compared with studies elsewhere, the findings in this study were lower than findings in Australia, where the prevalence of active trachoma among children was $40 \%$ at baseline, $33 \%$ at 7 months' follow-up and $37 \%$ at twenty one month's follow up. ${ }^{22}$ Also in Nepal, the prevalence was $31 \%$ in children aged 4-10 years, ${ }^{23}$ and in Yemen, the preliminary age specific findings had it that, $30 \%$ of children aged less than 10 years had TF/TI, with a range of $28 \%$ to $35 \%$ in the different governorates. ${ }^{24}$ In a similar study in Yemeni school pupils, an overall rate of infection of active trachoma was $45.9 \%{ }^{25}$ and the prevalence of active trachoma in school children in rural villages of the Qalyub Governorate of Egypt was 26\%. ${ }^{26}$ Similarly, other studies have shown higher prevalence of active trachoma as in Jimma zone Ethiopia, Chad, The United Republic of Tanzania, Guinea and Senegal where the prevalence of active trachoma in children under 10 years of age, were $35.7 \%{ }^{27} 31.5 \%{ }^{28}$, $48 \%{ }^{29}, 32.3 \%{ }^{30}$ and $53.6 \%{ }^{31}$ respectively. It could 
be seen that some of these studies were carried out in areas with higher socioeconomic status than the study environment, but the study environment has aridity and lack of water as a common denominator with these study areas. Therefore dry environment and unavailability of adequate water supply could be responsible for presence of active trachoma the in the study area.

In contrast to above studies with higher prevalence in children with active trachoma, other studies have shown lower prevalence compared to the findings in this study. In Morocco the prevalence, of TF/TI in children under 10 years in four provinces were: Errachidia, 9.4\%\%; Figuig, 0.1\%; Ouarzazate, $0.7 \%$; Tata, $5.2 \%{ }^{32}$ Similarly in Mwanza Region in Tanzania the prevalence of active trachoma was $5.5 \%$ though the prevalence was $15.5 \%$ in the poorest school. $^{33}$ In Luapula Valley Zambia, Senegal, and Ghana, the prevalence of active trachoma for children was $13.2 \%,{ }^{34} 10.8 \%{ }^{35}$ and $16.1 \%,{ }^{32}$ respectively. At the same time, it could be seen that all these countries with the presence of trachoma are developing countries with poor socioeconomic infrastructure.

There are studies with similar findings in prevalence of active trachoma in children with findings of this study as shown in a study of Yanomami Indians in the State of Amazonas in Brazil, where the prevalence of active trachoma was $24.9 \%$ in children. ${ }^{36}$ Similarly, in Morocco in the Zagora region, the prevalence of active trachoma was $22.1 \%$ in children. ${ }^{32}$ Active trachoma is usually present in areas of low rainfall and low atmospheric humidity coupled with poor socioeconomic development, poor environmental sanitation and lack of adequate water supply. The presence of active trachoma in the study area could probably be due to dry weather condition of the study environment and poor socioeconomic development. There could be a possibility that apart from socioeconomic factors, there is a direct link between $C$. trachomatis and dry arid and sandy conditions. The higher prevalence of active trachoma in boys could probably be that, the boys are more playful and dirty while the girls involvement in domestic chores afford them the opportunity to have greater access to water to clean their hands and faces. In both schools, prevalence of active trachoma was higher in the age groups 5 to 9 years. This finding could be due to lack of personal hygiene and unhealthy plays or habits associated with these age groups.

\section{References:}

1. Thylefors B. The World Health Organization's programme for the prevention of blindness. International Ophthalmology 1990; 14: 211219.

2. Mun oz B, West S. Trachoma: the forgotten cause of blindness. Epidemiologic Reviews 1997; 19: 205217.

3. Nicole F.H, Robin L. B, Simon C., Denise M., Hannah F. \& David C.W. M. Efficacy of oral azithromycin versus topical tetracycline in mass treatment of endemic trachoma, Bulletin of the World Health Organization 2001; 79 (7) 632-640.

4. Lietman $\mathrm{T}$, Whitcher J. Chlamydial conjunctivitis. Ophthalmology Clinics of North America 1999; 12: 2132.

5. Kocak-Midillioglu I. Penetrating keratoplasty in patients with corneal scarring due to trachoma. Ophthalmic Surgery and Lasers 1999; 30: 734741.

6. Report of the First Meeting of the WHO Alliance for the Global Elimination of Trachoma. Geneva, Switzerland 30 June1 July1997; 16- 18.

7. World Health Organization. Future approaches to trachoma control: report of a global scientific meeting, Geneva, 1720 June1996.Geneva, WHO Programme for the Prevention of Blindness and Deafness 1996; 22 -25.

8. Report of the Third Meeting of the WHO Alliance for the Global Elimination of Trachoma. Ouarzazate, Morocco 1920 October1998; 23-30.

9. Schachter J, Dawson CR. The epidemiology of trachoma predicts more blindness in the future. Scand J Infect Dis Suppl 1990; 69:55-62.

10. Taylor KI, Taylor HR. Distribution of azithromycin for the treatment of trachoma [commentary]. British Journal of Ophthalmology 1999; 83: 134135.

11. Hiratsuka Y., Ono K., Kanai, A. The present state of blindness in the world Nippon-Ganka-Gakkai-Zasshi 2001 Jun; 105(6): 369-73.

12. Lewallen $\mathrm{S}$, Courtright $\mathrm{P}$. Blindness in Africa: present situation and future needs.Br J Ophthalmol 2001 Aug; 85(8):897-903.

13. Taylor HR. Trachoma: Int Ophthalmol 1990 May; 14(3):201-4.

14. National Population Commission Census 1991.

15. Bama LGA unpublished report 2003 3-5.

16. West $\mathrm{S}$. Nonocular chlamydia infection and risk of ocular reinfection after mass treatment in a trachoma hyperendemic area. Investigative Ophthalmology and Visual Science 1993; 34: 31943198.

17. Epi Info Version 2002.

18. Maby D, Bailey R. Eradication of trachoma worldwide. British Journal of Ophthalmology 1999; 83: 12611263.

19. Nimzing F. J: Annual Review meeting TCP Presentation; Global 2000/The Carter Centre 2002; 6-7.

20. Evans TG, Ranson MK. The global burden of trachomatous visual impairment: II. Assessing burden. Int Ophthalmol. 1995-96; 19(5):271-80.

21. Apiafi D. I. Status of trachoma Survey Activities and Prevalence in Borno State of Nigeria. Trachoma Survey in Borno and Participation at GET Meeting, Geneva 2000; 5-6

22. Ewald DP, Hall GV, Franks CC. An evaluation of a SAFE-style trachoma control program in Central Australia. Med JAust. 2003 Jan 20; 178(2):65-8. 
23. Brilliant GE. The epidemiology of blindness in Nepal: report of the 1981 Nepal Blindness Survey. Chelsea, MI, The Seva Foundation 1988; 12-14.

24. Report of the Sixth Meeting of the WHO Alliance for the Global Elimination of Blinding Trachoma Geneva, Switzerland(5-7 November 2001)World Health Organization 2002; 13-30.

25. Sallam TA, Raja'a YA, Al-Zubiery TK, Al-Shaibani KS, Al-Shamiri AA, Thobala HS and others. Chlamydia trachomatis infections among Yemeni school pupils in relation to environmental conditions. Saudi Med J. 2003 Jan; 24(1):84-7.

26. Barsoum IS, Mostafa MS, Shihab AA, el Alamy M, Habib MA, Colley DG. Prevalence of trachoma in school children and ophthalmological outpatients in rural Egypt: Am J Trop Med Hyg 1987 Jan;36(1):97101.

27. Zerihun N. Trachoma in Jimma zone, south western Ethiopia. Trop Med Int Health 1997 Dec; 2(12):1115-21.

28. Madani MO, Huguet P, Mariotti SP, Dezoumbe D, Tosi C, Djada D, Negrel AD. Trachoma in Chad: Results of an epidemiological survey: Sante. 2003 Jan-Mar; 13(1):915.

29. Bobo LD. Severe disease in children with trachoma is associated with persistent Chlamydia trachomatis infection. Journal of infectious diseases 1997; 176: 1524-1530.

30. World Health Organization. Future approaches to trachoma control: report of a global scientific meeting, Geneva, 1720 June1996.Geneva, WHO Programme for the Prevention of Blindness and Deafness 1996; 22 -25.
31. Moalic E, Dueymes JM, Baron R, Le Flohic AM; Crosssectional survey of trachoma in school age children in the region of Thies (Senegal). Pediatr Infect Dis J. 2000 Oct; 19(10):979-83.

32. Report of the Sixth Meeting of the WHO Alliance for the Global Elimination of Blinding Trachoma Geneva, Switzerland(5-7 November 2001)World Health Organization 2002; 13-30.

33. Wedner SH, Ross DA, Balira R, Kaji L, Foster A.Prevalence of eye diseases in primary school children in a rural area of Tanzania. Br J Ophthalmol. 2000 Nov; 84(11):1291-7.

34. Sukwa TY, Ngalande TC, Mwandu DH, Siziya S, Mukunyandela M. Prevalence and distribution of trachoma in the Luapula Valley, Zambia. East Afr Med J 1992 Jan; 69(1):34-6.

35. Saal MB, Schemann JF, Saar B, Faye M, Momo G, Mariotti S, Negrel AD Med. Trachoma in Senegal: results of a national survey Trop (Mars). 2003; 63(1): 53.

36. Paula JS, Medina NH, Cruz AA; Trachoma among the Yanomami Indians. Braz J Med Biol Res. 2002 Oct; 35(10):1153-7.

Acknowledgement: The authors wish to thank HKI Nigeria and its Staff for sponsoring this research work and also acknowledges the contributions of Borno State Trachoma control team, Hajia Iyabo, Mallam Salleh and Alhaji Kunduga. 